\title{
ANALISIS PIGMEN KLOROFIL PADA ALGA Kappaphycus alvarezii YANG DIBUDIDAYAKAN DI TELUK TOTOK KABUPATEN MINAHASA TENGGARA
}

\author{
(Analysis of the Pigment Chlorophyll on the Algae Cappaphycus Alvarezii Cultivated \\ in Bay Totok Southeast Minahasa Regency)
Raja Doli ${ }^{*}$, Desy M. H. Mantiri', Darus Saadah Paransa ${ }^{1}$, Kurniati Kemer ${ }^{1}$, Rosita A.J. Lintang ${ }^{1}$, Sipriana S. Tumembouw ${ }^{2}$ \\ Program Studi IImu Kelautan, FPIK Unsrat Manado. \\ Program Studi Budi Daya Perairan, FPIK Unsrat Manado \\ ${ }^{*}$ Correspondence Author : dmh mantiri@unsrat.ac.id
}

\begin{abstract}
Macroalgae is a chlorophyll plant and its body is thallus and is able to live in polluted waters. The research was conducted with the intention of knowing the content of chlorophyll pigment and comparing the concentration of chlorophyll on Kappaphycus alvarezii using the formula Jeffrey and Humprey (1975) and Harbone (1987). The results obtained to separate the chlorophyll pigment on Kappaphycus alvarezii using the thin layer chromatography (KLT) method, thus obtained the pigment identified from Kappaphycus alvarezii namely chlorophyll a.
\end{abstract}

Keywords: Kappaphycus alvarezii, thin-layer chromatography. Chlorophyll.

Abstrak

Makroalga merupakan tumbuhan yang berklorofil dan tubuhnya berupa thallus serta mampu hidup pada perairan tercemar. Penelitian ini dilakukan dengan tujuan untuk mengetahui kandungan pigmen klorofil dan membandingkan konsentrasi klorofil pada Kappaphycus alvarezii menggunakan rumus Jeffrey dan Humprey (1975) dan Harbone (1987). Hasil yang diperoleh untuk memisahkan pigmen klorofil pada Kappaphycus alvarezii menggunakan metode Kromatografi Lapis Tipis (KLT), sehingga diperoleh pigmen yang teridentifikasi dari Kappaphycus alvarezii yaitu klorofil a.

Keywords : Kappaphycus alvarezii, Kromatografi Lapis Tipis. Klorofil. 


\section{PENDAHULUAN}

Alga adalah sekelompok organisme yang bervariasi meliputi bentuk, ukuran, warna (pigmen) dan komposisi senyawa kimia lainnya (Leibo $d k k, 2016$ ). Alga adalah organisme autotrof, salah satu penyumbang oksigen terbesar di suatu perairan. Proses pertumbuhan alga membutuhkan nutrien dari lingkungan perairan. Lingkungan yang tercemar dapat mempengaruhi pertumbuhan dan metabolisme pada alga (Dawes, 1998). Keberadaan alga di lingkungan perairan memiliki fungsi sebagai parameter biologi dan memberikan informasi untuk mengevaluasi keadaan, kualitas dan kesuburan perairan (Awal dkk, 2014).

Kappaphycus alvarezii adalah salah satu jenis alga dari kelas Rhodophyceae dan merupakan salah satu alga carragenophytes, yaitu alga penghasil karagenan. Kappaphycus alvarezii umumnya terdapat di daerah yang relatif bersih, kebanyakan tumbuh di daerah pasang surut (intertidal) atau pada daerah yang selalu terendam air (subtidal) melekat pada substrat di dasar perairan yang berupa karang. Umumnya alga tumbuh dengan baik di daerah pantai terumbu (reef), karena di tempat inilah beberapa persyaratan untuk pertumbuhannya banyak terpenuhi, diantaranya faktor kedalaman perairan, cahaya, substrat dan gerakan air. Habitat khas adalah daerah yang memperoleh aliran laut yang tetap dengan variasi suhu harian yang kecil dan substrat batu karang mati (Aslan, 1998).

\section{METODE}

\section{Lokasi Penelitian}

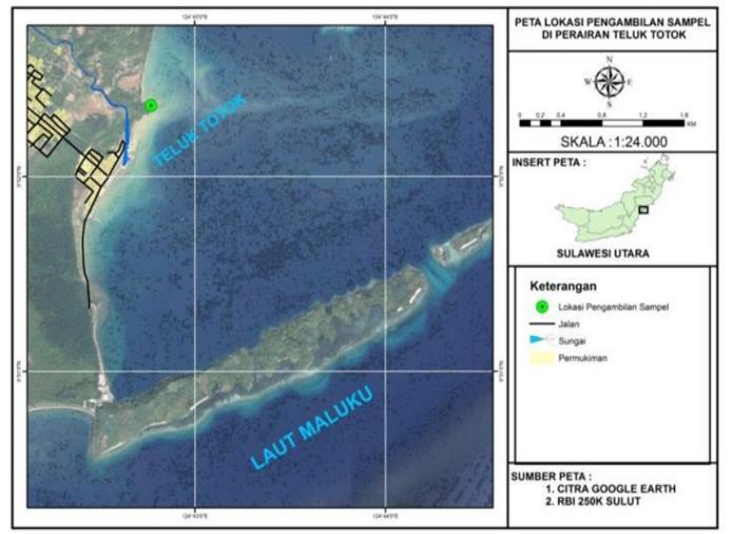

Gambar 1. Peta Lokasi Penelitian di Teluk

Totok, Kabupaten Minahasa Tenggara

Pengambilan sampel dilakukan di Teluk Totok, Kec. Belang, Minahasa Tenggara, Sulawesi Utara pada September. Secara geografis tempat pengambil sampel berada di N 0055'24.1" dan E 12442'47.4" (Gambar 1). Ekstraksi, dan Kromatografi Lapis Tipis (KLT) dilaksanakan di Laboratorium Teknologi Akuakultur; penimbangan alga dilaksanakan di Laboratorium Kesehatan Ikan Fakultas Perikanan dan IImu Kelautan, Universitas Sam Ratulangi, Manado dan serapan spektrofotometer dilaksanakan di Laboratorium Farmasi Fakultas Matematika dan IImu Pengetahuan Alam, Universitas Sam Ratulangi, Manado.

\section{Teknik Pengambilan Sampel}

Sampel yang digunakan dalam penelitian ini adalah jenis alga Kappaphycus alvarezii yang memiliki warna thallus coklat dan hijau yang diambil dari Perairan Belang kemudian dibudidaya di Teluk Totok (Hosea, 2019). Thallus alga Kappaphycus alvarezii coklat dan hijau dibudidaya selama 6 minggu. Selama pembudidayaan, setiap 2 minggu thallus Kappaphycus alvarezii coklat dan hijau diambil untuk dianalisis kandungan klorofil. Pengambilan sampel dilakukan yaitu 
dengan memotong thalus alga dengan menggunakan pisau. Selanjutnya sampel yang telah dipotong dimasukkan ke dalam cool box kemudian dibawa ke Laboratorium Teknologi Akuakultur Fakultas Perikanan dan IImu Kelautan, Universitas Sam Ratulangi dan dimasukkan ke dalam freezer dengan suhu $-8^{\circ} \mathrm{C}$.

\section{Proses Ekstraksi}

Sampel yang disimpan didalam freezer, selanjutnya dilakukan proses ekstraksi. Sebelum dilakukzan proses ekstraksi Kappaphycus alvarezii coklat dan hijau dilakukan penimbangan masingmasing sampel dengan berat 15 gram, kemudian sampel dipotong kecil-kecil dengan menggunakan gunting.

Selanjutnya dilakukan penggerusan dengan menggunakan lumpang dan alu. Selama penggerusan ditambahkan aseton sebanyak $10 \mathrm{ml}$. Penggerusan dilakukan secara terus menerus hingga larutan berubah warna dengan tujuan untuk mendapatkan ekstrak klorofil secara maksimal. Proses penggerusan sampel alga tampak pada Gambar 2.

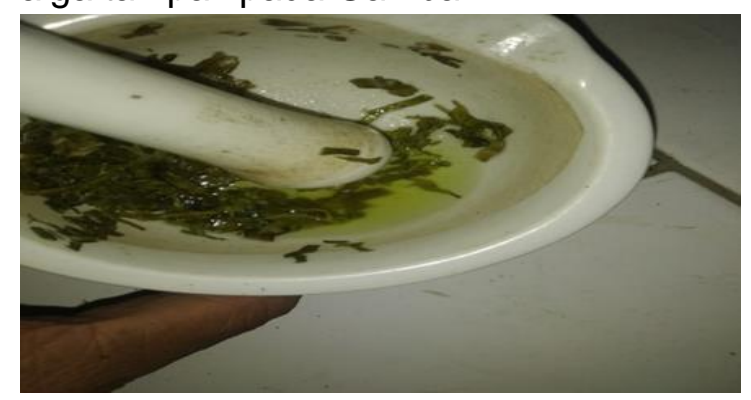

Gambar 2. Penggerusan Thallus

\section{Spektrofotometer}

Kappaphycus alvarezii

Spektrofotometer Uv-Vis adalah alat yang digunakan untuk mengukur transmitansi, reflektansi dan absorbsi dari cuplikan sebagai fungsi dari panjang gelombang. Spektrofotometer sesuai dengan namanya merupakan alat yang terdiri dari spektrometer dan fotometer. Spektrometer menghasilkan sinar dari spektrum dengan panjang gelombang tertentu dan fotometer adalah alat pengukur intensitas cahaya yang ditransmisikan atau yang diabsorbsi.

Spektrofotometer digunakan untuk mengukur energi cahaya secara relatif jika energi tersebut ditransmisikan, direfleksikan atau diemisikan sebagai fungsi dari panjang gelombang. Suatu spektrofotometer tersusun dari sumber spektrum sinar tampak yang sinambung dan monokromatis. Sel pengabsorbsi untuk mengukur perbedaan absorbsi antara pembanding.

\section{Analisis Data Hasil Serapan Spektrofotometer}

Data hasil analisis serapan panjang gelombang digunakan untuk menentukan menghitung konsentrasi klorofil total dan klorofil a melalui serapan maksinum spektrofotometer diantara panjang gelombang 350 - $700 \mathrm{~nm}$. Konsentrasi pigmen total dan klorofil ditentukan menggunakan dua rumus matematis yaitu berdasarkan perhitungan Harbone (1987) dan Jeffrey dan Humprey (1975).

1. Berdasarkan rumus matematis Harbone (1987), spektrogram yang membentuk puncak serapan spektrofotometer pada 663 dan $645 \mathrm{~nm}$ pada ekstrak pigmen total dalam aseton dihitung dengan rumus berikut :

a. Klorofil total $=17,3 \mathrm{E}_{646}+7,18 \mathrm{E}_{633} \mathrm{mg} / \mathrm{l}$

b. Klorofil a $=12,21 \mathrm{E}_{663}+2,81 \mathrm{E}_{646} \mathrm{mg} / \mathrm{l}$

2. Berdasarkan rumus matematis Jeffrey dan Humprey (1975), dengan rumus berikut :

Klorofil a

$$
=11,85\left(E_{664}\right)-1,54\left(E_{647}\right)-0,08 \quad\left(E_{630}\right),
$$
$\mathrm{mg} / \mathrm{l}$

Keterangan : $\mathrm{E}=$ absorbansi pada panjang gelombang pada spektrofotometer

\section{Proses KLT}

Untuk mendapatkan pigmen klorofil pada pigmen ekstrak total alga dilakukan 
melalui pemisahan Kromatografi Lapis Tipis (KLT). Diawali dengan penyiapan sampel yang telah diekstrak, plat silika sebagai fase diam dan larutan pengembang $\mathrm{Pe}$ : Aseton (70:30) sebagai fase gerak. Setiap fraksi yang diperoleh pada proses KLT selanjutnya dilakukan serapan puncak maksimum spektrofotometer. Mantiri (1997), mengemukakan bahwa tahap pengembangan menggunakan metode KLT untuk menentukan polaritas jenis pigmen pada alga dengan larutan pengembang yang paling baik adalah pengembang semipolar yaitu Pertroleum Eter (PE) dan Aseton.

Proses Kromatografi lapis tipis (KLT) mengikuti panduan Packer (1992).

1. Plat silika gel dengan ukuran $10 \times 10$ $\mathrm{cm}$ sebagai fase diam disediakan.

2. Plat silika gel dipanaskan dalam oven selama 3 jam dengan suhu $70^{\circ} \mathrm{C}$, lalu dimasukan ke dalam desikator untuk didinginkan.

3. Pembuatan kromatogram, menggambar garis horizontal diatas plat silika gel dengan masing-masing jarak $1 \mathrm{~cm}$ dari ujung bawah sebagai garis titik awal dan $1 \mathrm{~cm}$ dari ujung atas yaitu garis titik akhir sebagai batas larutan pengembang naik.

4. Kemudian buat 5 spot dengan pensil pada garis titik awal dengan masingmasing jarak $1 \mathrm{~cm}$.
5. Totolkan larutan ekstrak pigmen alga yang akan dianalisis pada setiap spot mengunakan pipet kapiler, penotolan larutan ekstrak pigmen alga pada plat silika dilakukan berulang-ulang sampai warnanya pekat.

6. Setelah sampel ekstrak pigmen alga ditotolkan pada spot yang terdapat pada titik garis awal, plat silika kemudian dimasukan ke dalam Chamber yang berisis larutan. Larutan yang digunakan sebagai fase gerak (pengembang) ialah Petroleum Eter : Aseton $(70: 30)$.

7. Setelah fase gerak atau larutan naik sampai ke batas garis titik akhir yang telah ditetapkan, plat silika kemudian diangkat dari chamber dengan menggunakan pinset.

8. Selanjutnya yaitu tahap deteksi atau visualisasi, mengamati warna setiap bercak yang timbul di atas plat silika gel.

9. Selanjutnya menghitung nilai $\mathrm{Rf}$ (Retardation factor) pada bercak yang muncul diatas permukaan plat silika gel.

10. Penentuan nilai Rf (Retardation factor) dilakukan dengan menghitung jarak yang ditempuh oleh senyawa dari titik asal dibagi dengan jarak yang ditempuh eluen dari titik asal.

11. Kemudian setiap fraksi digunting kecilkecil untuk diisolasi dengan menggunakan aseton sebanyak $5 \mathrm{ml}$ untuk mengidentifikasi jenis pigmen. 


\section{Hasil dan Pembahasan Identifikasi Sampel}

Identifikasi sampel terdapat warna thallus alga berbeda yang dibudidaya pada perairan totok, dimana kedua sampel tersebut memiliki ciri-ciri morfologi bentuk tubuh yang sama yaitu thallus berbentuk silindris, permukaan licin, percabangan ke berbagai arah dengan cabang-cabang utama keluar saling berdekatan ke daerah basal (pangkal), cabang-cabang pertama dan kedua tumbuh dengan membentuk rumpun yang rimbun. Ciri-ciri morfologi warna dimana sampel alga pertama berwarna coklat dan sampel kedua berwarna hijau. Berdasarkan panduan Trono (1997), sampel ini teridentifikasi sebagai $K$. alvarezii coklat dan $K$. alvarezii hijau, seperti yang tampak pada Gambar 3.

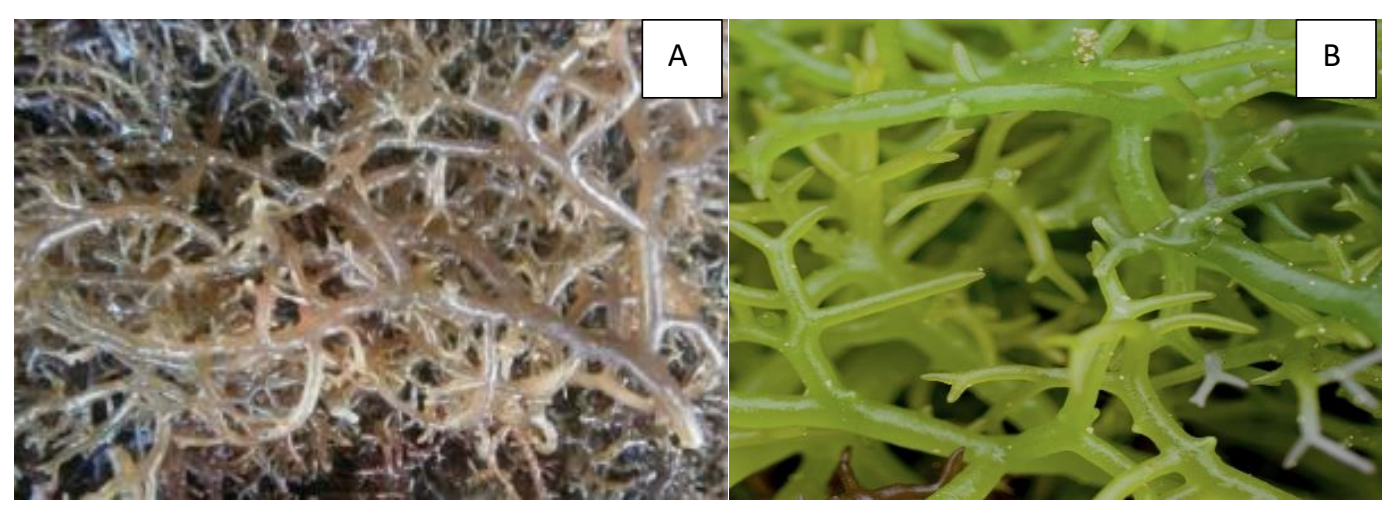

Gambar 3. (A) Kappaphycus alvarezii berwarna coklat dan (B) hijau

\section{Serapan Spektrofotometer Ekstrak Pigmen Total}

Pengambilan sampel Kappaphycus alvarezii thallus hijau dan coklat dari perairan belang dijadikan sebagai kontrol, kemudian dibudidayakan selama 6 minggu di perairan teluk totok. Pada minggu ke-2, ke-4 dan ke-6 diambil thallusnya untuk analisis pigmen.

Serapan spektrofotemeter pada ekstrak sampel kontrol dan ekstrak minggu ke-2, ke-4 dan ke-6 ekstrak yang dibudidayakan dapat menentukan konsentrasi pigmen Total dan konsentrasi Klorofil a. Penentuan tersebut mengikuti rumus matematis Harbone (1987) dan rumus matematis Jeffrey dan Humprey (1975). Bentuk spektrogram ekstrak pigmen total tampak pada Gambar di bawah ini 

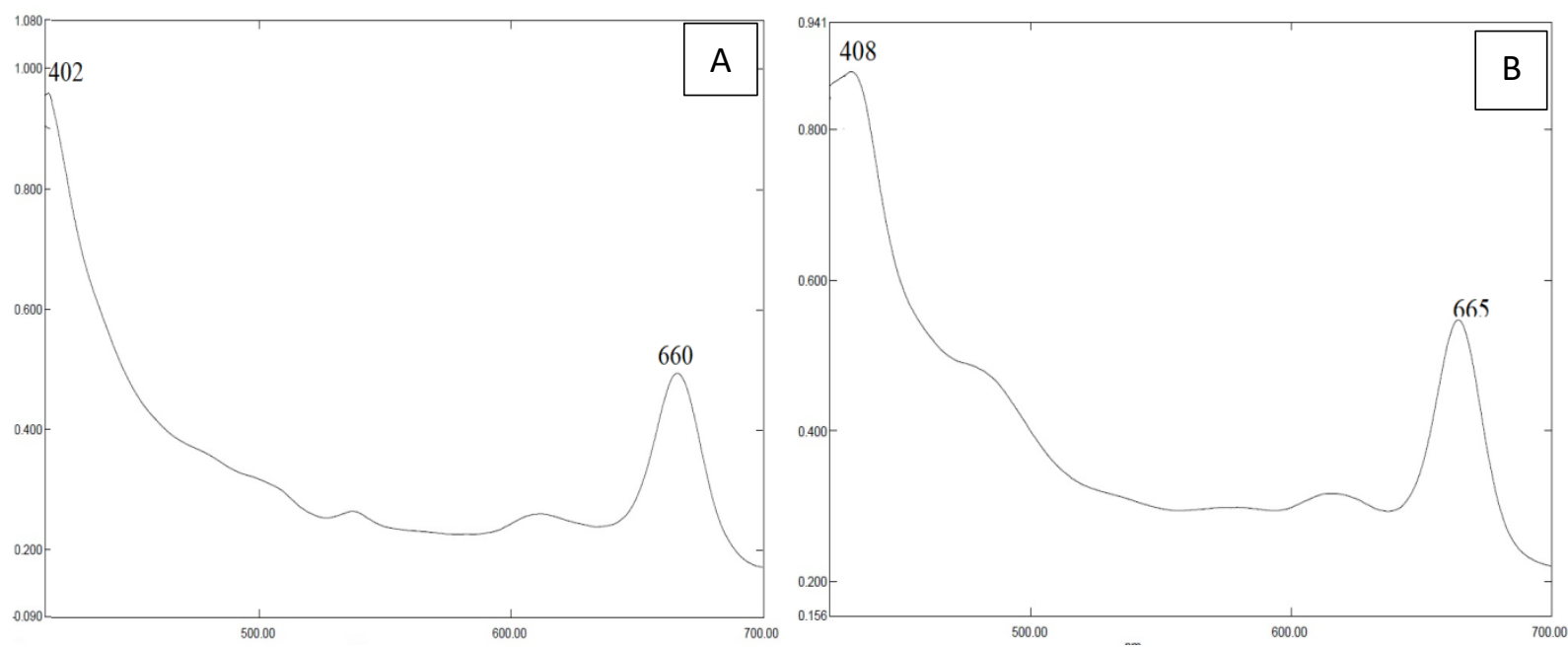

Gambar 4. Spektrogram ekstrak pigmen klorofil (A) thallus hijau dan (B) thallus coklat

Pada kurva diatas thallus hijau terlihat dua puncak pada panjang gelombang 402 dan $660 \mathrm{~nm}$. Pada thallus coklat terlihat puncak panjang gelombang pada 408 dan 665 nm. Kurva ini menunjukkan pigmen klorofil yang dimana puncak panjang gelombang berada pada $350-700 \mathrm{~nm}$.

\section{Konsentasi Pigmen Total dan Klorofil A Berdasarkan Harbone (1987)}

Serapan spektrofotometer ekstrak pigmen total thallus hijau dan coklat Berdasarkan rumus matematis Harbone (1987), dapat diketahui kandungan konsentrasi pigmen total dan konsentrasi pigmen klorofil A pada thalus hijau. seperti yang tampak pada Gambar 5.

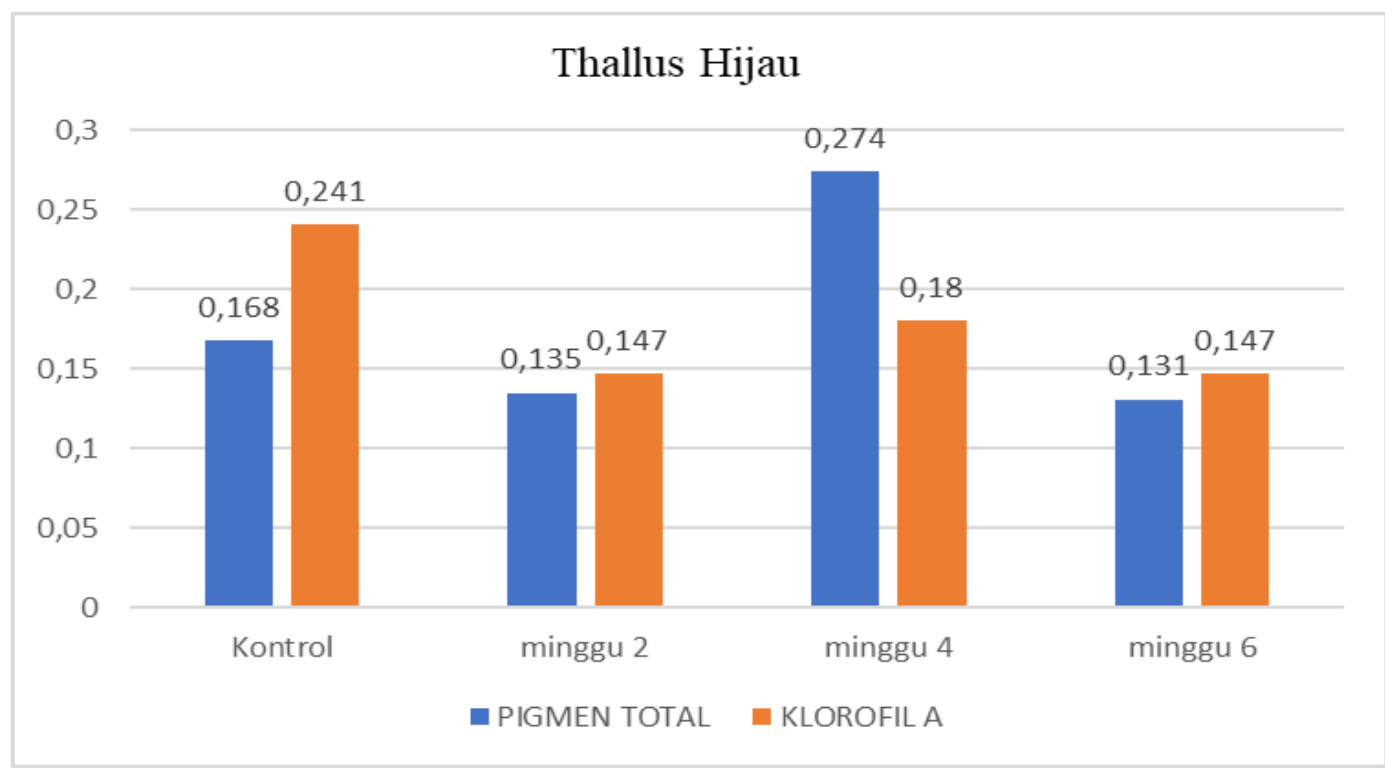

Gambar 5. Konsentrasi pigmen total dan klorofil a pada Thallus Hijau

Sampel Kappaphycus alvarezii thallus hijau yang diambil warna dari perairan Belang memiliki konsentrasi pigmen total rata-rata $0,168 \mathrm{mg} / \mathrm{l}$ dan konsentrasi klorofil a rata-rata adalah 0,241 $\mathrm{mg} / \mathrm{l}$. Setelah dibudidayakan di perairan teluk totok pada minggu kedua terjadi penurunan konsentrasi pigmen total dan klorofil a. Saat pemeliharaan di minggu ke4 terjadi peningkatan konsentrasi pigmen 
total dan klorofil a. Saat pemeliharaan di minggu ke-6 terjadi penurunan konsentrasi.

\section{Analisis Kromatografi Lapis Tipis Ekstrak Pigmen}

Hasil Pemisahan KLT pada ekstrak pigmen total thallus hijau dan coklat dengan larutan
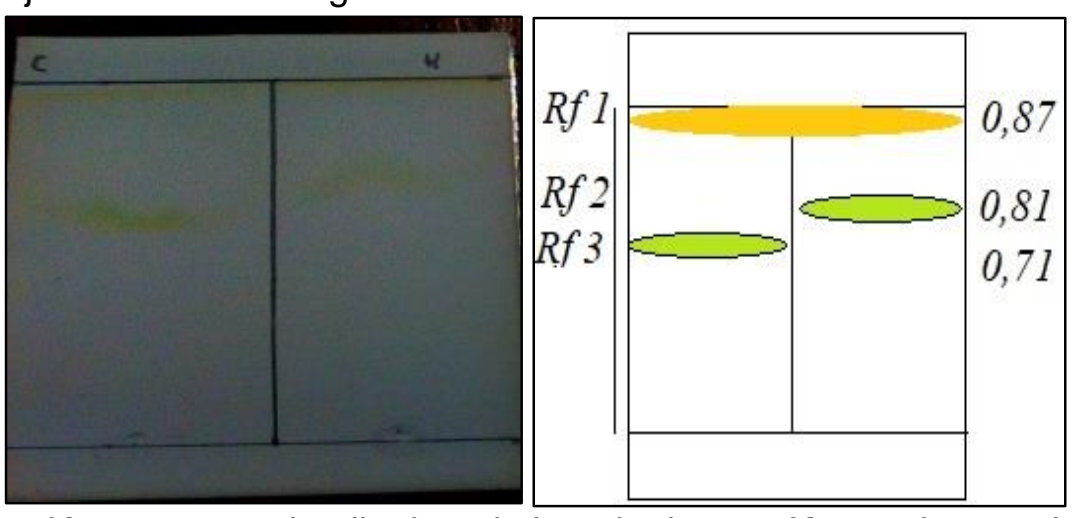

Gambar 6. Kromatogram hasil migrasi ekstrak pigmen Kappaphycus alvarezii dengan pengembang PE dan Aseton (70:30).

Tabel 1. Hasil analisis serapan spektrofotometer dengan larutan pengembang PE dan Aseton (70:30) dari ekstrak pigmen Kappaphycus alvarezii

\begin{tabular}{|l|l|l|l|}
\hline FRAKSI & WARNA & $\begin{array}{l}\text { PANJANG } \\
\text { GELOMBANG (nm) }\end{array}$ & JENIS PIGMEN \\
\hline 1 & Hijau & - & Tidak teridentifikasi \\
\hline 2 & Hijau & $409-665$ & Klorofil a \\
\hline 3 & $\begin{array}{l}\text { Hijau kekuning- } \\
\text { kuningan }\end{array}$ & $408-662$ & Klorofil a \\
\hline
\end{tabular}

Fraksi 1 hasil dari larutan pengembang PE dan aseton (70:30) tidak membentuk puncak serapan spektrofotometer sehingga fraksi tersebut tidak teridentifikasi. Menurut Stahl (1985), terbentuknya fraksi yang memudarnya di atas fase diam sehingga tidak terbentuknya serapan maksimum dari spektrofotometer.

Memudarnya warna pada fraksi yang terbentuk di atas plat silika disebabkan oleh beberapa hal antara lain akibat pengaruh suhu, kelembaban udara, kejenuhan ruangan akan pelarut, konsentrasi dan komposisi pelarut serta faktor utama yaitu cahaya. pengembangan Petroleum Eter (PE) dan Aseton dengan perbandingan $70: 30$. Terbentuk tiga fraksi dari hasil pemisahan KLT tersebut, pada fraksi 1 di atas plat silika gel terbentuk spot dengan warna hijau, tampak pada Gambar 6. 
spektrogram pada fraksi 2 dan 3 menunjukkan konsentrasi yang terdapat pada thallus coklat dan hijau ialah klorofil a, hal ini dibuktikan dengan puncak gelombang.

\section{Kesimpulan}

Pigmen yang terdapat pada Kappaphycus alvarezii warna hijau \& coklat adalah klorofil a. Konsentrasi pigmen klorofil a pada thaluss hijau \& coklat, klorofil

\section{DAFTAR PUSTAKA}

Aslan, L.M. 1998. Budidaya Rumput Laut. Jakarta: Kanisius. Hal. 13-15.

Awal J., H. Tantu., E.K.P. Tenriawaru, (2014). Identifikasi Alga (Algae) Sebagai Bioindikator Tingkat Pencemaran di Sungai Lamasi Kabupaten Luwu. Jurnal Dinamika. 5(2):21-34.

Britton, G., Jansen, S.L., Pfander, H. 1995. Caratenoids. Volume 1B. Spectroscopy. Basel, Switzerland.

Dawes, C. J. 1998. Marine botany, 2nd edition. John Wiley \& Sons, New York.

Harborne, J.B. 1987. Metode Fitokimia Penuntun Cara Modern Menganalisis Tumbuhan. Bandung : Penerbit ITB Bandung.

Hosea, 2019. Analisis Logam Timbal (Pb) Pada Kappaphycus alvarezii (Doty) Alga Merah Yang Dibudidaya Di Teluk Totok Minahasa tenggara, Sulawesi Utara. Manado

Jeffrey, S.W. and Humphrey, G.F. 1975. New Spectrophotometric Equations For Determining Chlorophylls a, b, c1 and c2 Inb Higher Plants, Algae and a pada thallus hijau mengalami penurunan pada minggu ke-2 yaitu $0,147 \mathrm{mg} / \mathrm{L}$, yang dimana pada alga kontrol terdapat 0,147 $\mathrm{mg} / \mathrm{L}$ kemudian pada thallus coklat alga kontrol mengandung klorofil a $0,190 \mathrm{mg} / \mathrm{L}$ dan pada minggu ke-2 mengalami penurunan $0,112 \mathrm{mg} / \mathrm{L}$. Analisis klorofil a dengan menggunakan rumus yang berbeda Harborne (1987) \& Jefrey \& Humphrey (1975) memperoleh hasil yang signifikan tidak berbeda berdasarkan pola diagram yang dianalisis.

Natural Phytoplankton. Biochem Physiol, 167 (88), pp. 191 - 194.

Leibo, R., D.M.H. Mantiri., G.S. Gerung, (2016). Uji Aktivitas Antioksidan Dari Ekstrak Total Alga Hijau Halimeda opuntia Linnaeus dan Halimeda macroloba Decaisne Dari Perairan Teluk Totok. Jurnal Pesisir dan Laut Tropis. 2(1):36.

Mantiri D.H.M., 1997. These. Nature, Loocalization et metabolism descarotenoids et des complexes carotenoproteiques au cours de L'Evolution Embryonnaire et Larvaire du Hommard Europeen Homarus Gammarus. Universite De Droit, D'economie Et Des Science D'aix Marzelle

Packer, L. 1992. Caratenoids. Part A In Metnods In Enzimology. Volume 213. Academic Press Inc. California.

Stahl, E., 1985. Analisis Obat Secara Kormatografi dan Mikroskopi. Penerbit ITB JI. Genesa Bandung

Trono, G. C. 1997. Seaweed Resources Of the Philipines. Buereau of Agricultural Research. Departement of Agricultural, Diliman, Quezon City. 